\title{
AS QUATRO DIMENSÕES DO DESPERTAR — SONHO, FANTASIA, DELÍRIO, ILUSÃO
}

Marco Antonio Coutinho Jorge

Psiquiatra, psicanalista, diretor do Corpo Freudiano do Rio de Janeiro, professor-adjunto do Instituto de Psicologia da Uerj, membro correspondente do Mouvement du Coût Freudien (Paris), membro correspondente da Association Insistance (Paris/ Bruxelles), autor de Fundamentos da psicanálise de Freud a Lacan, vol.1: As bases concetuais (Rio de Janeiro, Jorge Zahar, 2000)
RESUMO: Experiência do despertar do sentido, a psicanálise é uma descoberta que visa revelar aquilo que a religião oculta, pois ela opera sobre o campo do sentido de modo inverso ao da religião. Por isso, a obra de Freud como que desemboca na análise da religião, como se ela estivesse desde 0 início destinada a isso. A oposição radical entre psicanálise e religião resi de na forma antinômica pela qual ambas operam sobre o campo do sentido: a primeira visa obter um efeito de sentido real e a segunda, um fechamento imaginário desse campo.

Palavras-chave: Sentido, sonho, fantasia, delírio, ilusão.

ABSTRACT: The four dimensions of awakening: dream, fantasy, delusion, illusion. As an experience of the awakening of the meaning, psychoanalysis is a discovery which aims at revealing that which religion covers up, in that it operates in the field of meaning in an exact opposition to the latter. That is why Freud's work leads to the analysis of religion, as if it were destined towards it, from its very beginning. The radical opposition between psychoanalysis and religion resides in the antinomic fashion in which they both operate in the field of meaning: while the first aims at obtaining an effect of real meaning, the second is geared towards an imaginary closure of this field.

Keywords: Awakening, dream, fantasy, delusion, illusion.

"O inconsciente é muito exatamente a hi pótese de que a gente não sonha apenas quando dorme." J. LACAN, Une pratique de bavardage.

* Este artigo é parte do trabalho apresentado no colóquio "Freud et Vienne", organizado pela Association Insistance (Paris/ Bruxelas) e realizado em Viena de 13 a 15 de junho de 2003, sob os auspícios do Institut Français de Vienne e do Freud Museum (Berggasse 19). 
A partir da definição dos registros do imaginário e do real que é dada a partir - segundo o ideal de simplicidade (LACAN, 1962-63/ 2004), que ele próprio aspirava para seu ensino - e precisa entre el es: 0 imaginário é o sentido; já o real, diz Lacan, ele é o "avesso do imaginário", ele é o não-sentido, o não-senso, o sentido em branco, 0 ab-sens, o sentido ausente. No seminário Nomina non sunt consequentia rerum, Lacan precisa a esse respeito: "Há uma coisa que, de todo modo, é certa, se é que al guma coisa possa sê-lo, é que a idéia mesma de real comporta a exclusão de todo sentido. Não é senão na medida em que o real é esvaziado de sentido que nós podemos apreendê-lo um pouco [...]" (LACAN, 1977a/ 1978, p.12).

Cabe-nos acrescentar que, dentro dessa perspectiva, o simbólico pode ser definido como sendo da ordem do duplo sentido, o que é congruente com toda a teoria freudiana da linguagem destacada por Lacan em sua lógica do significante. 0 extenso segmento da obra de Freud sobre os pares antitéticos, apresentado em al guns textos princeps como A significação antitéica das palavras primitivas (FREUD, 1911a/ 1996) e 0 estranho (FREUD, 1919/ 1996), é a evidenciação, na obra de Freud, da binariedade inerente à estrutura do significante que, representando sempre 0 sujeito para outro significante, jamais comparece, a não ser por meio do par, e, particularmente, do par antitético (JORGE, 2000, p.103).Vê-se, aqui, que o simbólico, o campo do duplo sentido, é o registro que se situa como o verdadeiro articulador do sentido com o não-sentido, isto é, do imaginário com o real. A operação analítica, no que ela se desenrola no campo da linguagem, retira toda sua força desse poder do duplo sentido, inerente ao registro do simbólico, de produzir essa articulação do sentido com o não-sentido.

0 despertar é um termo empregado por Lacan. É também um termo utilizado por Freud. Mais do que isso, esse termo parece designar o cerne do que está em jogo na experiência psicanalítica. Do que a psicanálise é uma experiência do despertar, então, cabe logo indagar? Um despertar para o mais-além do sentido narcísico e, logo, imaginário. E sabemos que o sentido está precisamente no cerne do discurso da neurose individual e da neurose coletiva que, para Freud, representa a religião.

\section{O DESPERTAR DO SENTIDO E SUAS QUATRO DIMENSÕES: SONHO, FANTASIA, DELÍRIO...}

Nascida do abandono da técnica da hipnose, ${ }^{1}$ a psicanálise é uma experiência que, ao contrário de hipnotizar o sujeito, visa revelar aquilo que já o hipnotiza desde

\footnotetext{
${ }^{1}$ A antinomia entre psicanálise e hipnose foi salientada por Elisabeth Roudinesco (1989, p.162) ao observar que, a cada vez que uma grave crise acomete a psicanálise, a hipnose retorna enquanto um verdadeiro sintoma.
} 
sempre, desde sua própria constituição. A alienação, por ser um "fato mesmo do sujeito", segundo Lacan, ou seja, estruturante, nem por isso deixa de ser alienação. 0 despertar em jogo na análise indica, por sua vez, o caminho da separação.

$\mathrm{Na}$ obra de Freud, a abordagem do sentido pode ser depreendida em quatro grandes segmentos conceituais que foram tomados por ele, sucessivamente, numa espécie de seqüência lógica, em que um conceito levava ao outro: sonho, fantasia, delírio, ilusão. A análise de cada um desses elementos representou uma etapa na construção de uma experiência do despertar do sentido.

A obra de Freud se inaugura com a Deutung dos sonhos e, a partir dela, é a operação sobre o campo do sentido que ele irá operar. A interpretação dos sonhos inaugura a descoberta da psicanálise e, para Freud, a função do sonho é fundamentalmente a de ser um "guardião do sono". Na carta de 9/6/ 1899, durante o período de escrita de A interpretação dos sonhos, Freud escreve a Fliess: "Invariavelmente, o sonho visa a realizar um desejo que assume diversas formas. É o desejo de dormir! Sonhamos para não ter que acordar, porque queremos dormir. Tant de bruit [ pour une omelette]..." (FREUD, 1986, p.355). No seminário sobre 0 avesso da psicanálise, na lição de 21/ 1/ 1970, Lacan observa o quanto há de enigmático nesse deséo de dormir que Freud anuncia no mecanismo do sonho. "O desejo de dormir é, de fato, o maior enigma” (LACAN, 1969-70/ 1992, p.54), diz Lacan, e salienta que Freud não situa aquilo que determina a operação do sonho como uma necessidade de dormir, schlafen Bedürnis, mas sim como um desejo de dormir,W unsch zu schafen. Lacan prossegue, comentando que "o curioso équeFreud completa essa indicação com o seguinte - a pessoa desperta do sonho justamente no momento em que poderia deixar escapar a verdade, de sorte que só acordamos para continuar sonhando - sonhando no real, ou, para ser mais exato, na realidade" (LACAN, 1969-70/ 1992, p.54).

0 sonho, ao realizar de modo alucinatório o desejo - e o desejo é sempre sustentado pela fantasia ${ }^{2}$ - , está a serviço do adormecimento, e é precisamente naquele momento em que algo do real tenta imiscuir-se no sonho, como no sonho de angústia, que o sujeito acorda. Paradoxalmente, o sujeito acorda, diz Lacan, para prosseguir dormindo, isto é, fantasiando. Às vezes, durante o próprio sonho de angústia, dizemos para nós mesmos a fim de evitar o despertar que se insinua: "Afinal de contas, isto é apenas um sonho!" (PEIXOTO, 2003, p.73).

0 trabalho de escrita do livro sobre os sonhos - centrado, sobretudo, em sua própria análise - , custou caro a Freud, como ele atesta em sua correspondência da época, quando diz que "colocar isso no papel me é mais difícil do que qualquer outra coisa" (FREUD, 1986, p.269). E ainda: "Estou completamente

2 "A fantasia, em seu uso fundamental, é aquilo mediante o qual o sujeito se sustenta no nível de seu desejo evanescente" (LACAN, 1958/ 1998, p.643). 
mergulhado no [livro do] sonho, escrevendo oito a dez páginas por dia [...] Meu estilo, infelizmente, tem estado ruim, porque me sinto bem demais fisicamente; tenho que estar me sentindo um pouco mal para escrever bem" (FREUD, 1986, p.370-1) . 0 período que sucede a escrita do livro é de profunda depressão (FREUD, 1986, p.372).

Há uma relação íntima entre o sonho e a fantasia. Se todo sonho éa realização de um desejo, a fantasia é o suporte do desejo. "Nossos sonhos nada mais são do que fantasias" 3 - Freud frisa isto no artigo "O poeta e o fantasiar" (1908/ 1996, p.131) - , que sofreram a ação da censura e emergiram deformadas e distorcidas. A mesma ação da fantasia inconsciente, em torno da qual o sonho e o devaneio ( fantasia consciente) se constroem, irá constituir para o sujeito, na vida de vigília, sua relação com a realidade, ou, melhor dizendo, sua própria realidade, uma vez que a realidade é, em essência, realidade psíquica.

A fantasia ocupa a elaboração freudiana durante um longo período, que podemos denominar "período áureo da fantasia", situado entre 1907 e 1911, que se estende desde 0 ensaio sobre a Gradiva de Jensen até 0 texto metapsicológico sobre a fantasia, "Formulações sobre os dois princípios do funcionamento mental". Durante esse período, Freud tematiza a questão da fantasia em diversos pequenos artigos, todos eles dedicados a tratar da fantasia em suas diferentes manifestações, em sua relação com o sintoma e 0 ataque histérico, as teorias sexuais infantis e a criação literária.

0 que interessa observar é que, apenas ao cabo desse longo período de estudo aprofundado da fantasia, Freud consegue extrair a complexa lógica inerente ao delírio na psicose: em 1910, Freud escreve o texto sobre o caso Schreber e também o artigo metapsicológico já citado sobre a fantasia: "Formulações sobre os dois princípios do funcionamento mental", ambos publicados em conjunto em 1911, no mesmo volume da revista Jahrbuch. A postulação freudiana do delírio enquanto uma tentativa de cura da psicose - isto é, segundo minha hipótese descrita a seguir, enquanto tentativa de restabelecer o plano fantasístico rompido pelo fracasso do recalque originário na psicose - não pôde prescindir da compreensão da função essencial da fantasia no psiquismo: uma verdadeira função de "ponte" entre o princípio de prazer e o princípio de realidade. A esse respeito, é digno de nota que é precisamente em "Formulações sobre os dois princípios" queFreud introduz, pela primeira vez em sua obra, a oposição entre princípio de prazer e princípio de realidade (FREUD, 1911b/ 1996, p.224).

3 Freud recorre à "sabedoria da língua" e ilustra com o termo Tagtraum (devaneio), correlativo ao inglês daydream, literal mente sonho diurno, essa íntima relação entre sonho efantasia (FREUD, 1908/ 1996, p.131). 
Minha hipótese: a fantasia fundamental só entra em cena a partir da operação do recalque originário, cujo efeito primordial será o da instalação dessa fantasia fundamental como uma espécie de escudo protetor em relação ao real do gozo. Caso a fantasia não seja instaurada, ou seja, caso haja uma falha no recalque originário, como ocorre na psicose, a pulsão de morte passa a operar de forma direta e sem freio, e é como uma tentativa de substituir a falha da instauração da fantasia inconsciente que o psicótico construirá seu delírio. 0 delírio é, na psicose, uma tentativa de suplência da não-instauração da fantasia fundamental.

A grande reviravolta que Freud operou em relação à concepção psiquiátrica das psicoses foi a de enunciar que o delírio não é a psicose, mas, ao contrário, a tentativa de cura da psicose. Ou seja, o delírio é a tentativa, mais ou menos exitosa - mais exitosa na paranóia, quando ele comparece de modo sistematizado, ${ }^{4}$ e menos exitosa na esquizofrenia - , de reconstituir este verdadeiro filtro da fantasia que opera na neurose de modo a proteger o sujeito do encontro com o real em jogo na pulsão de morte.

Pode-se compreender melhor, desse modo, aquilo que Freud se empenha em elaborar nos dois famosos artigos de 1924, "Neurose e psicose" (1924a/ 1996) e "A perda da realidade na neurose e na psicose" (1924b/ 1996): a perda que está em jogo aí, para Freud, não é tanto a da realidade, que, de fato, é perdida não só na neurose como também na psicose (como ele se apressa em retificar no segundo artigo, escrito apenas al guns meses depois do primeiro), quanto a da fantasia no caso da psicose. 0 encaminhamento dado ao conjunto dos dois artigos sugere isto, tanto mais quanto Freud os encerra postulando, ao final do segundo, o lugar central ocupado pela fantasia na neurose e pelo delírio na psicose (1924b/ 1996, p.196-7). Freud conclui aí que, se a perda da realidade é comum à neurose e à psicose, o modo de substituir a realidade perdida é que será diferente em cada uma das duas estruturas: " 0 novo mundo externo, fantástico, da psicose quer substituir a realidade externa; por sua vez, o da neurose, prefere ligar-se, como o brinquedo das crianças, a um fragmento da realidade [...]" (FREUD, 1924b/ 1996, p.197).

Digamos, então, que o primeiro despertar promovido por Freud se deu em relação ao inconsciente, cuja "via régia" foi aberta pelo livro sobre os sonhos. Assim, seus três livros inaugurais, considerados por Lacan como obras "canônicas em matéria de inconsciente" (LACAN, 1957/ 1998, p.526), são como que três batidas de um tambor que, tal como as três sinetas do teatro, ou os três toc-toctoc do sujeito que bate à porta, anunciam a descoberta do inconsciente e promovem um despertar em relação à Outra Cena. ${ }^{5}$

\footnotetext{
4 Tal fato, por si só, explica o porquê de tanto Freud (caso Schreber) quanto Lacan (caso Aimée) abordarem a psicose, de saída, através da paranóia.

${ }^{5}$ Quanto à função do três na emergência do sujeito, cf. Os três tempos da lè: : [ ...] a gênese do Verbo requer a geração de um ritmo em três tempos" (DIDIER-WEILL, 1995/ 1997, p.110).
} 
O segundo despertar promovido por Freud tem a ver com a fantasia em sua relação com a pulsão sexual. Quanto a isso, cumpre ressaltar que o "período áureo" da fantasia é, por um lado, precedido pela introdução do conceito de pulsão, em 1905, nos "Três ensai os", e, por outro, é sucedido, em 1914, pelo advento do ensaio de "Introdução ao narcisismo" (1914/ 1996), no qual Freud dá seu primeiro passo rumo ao segundo dualismo pulsional.

0 que é a fantasia - que vai, em seu largo escopo, da fantasia inconsciente ao devaneio - , senão a manifestação mais pal pável no psiquismo da insatisfação inerente à própria pulsão sexual? A perda de gozo inerente à entrada do sujeito no mundo da linguagem, ou seja, na ordem simbólica, tem como corolário a entronização da fantasia como verdadeira "promessa de gozo" ao alcance do sujeito. É a ela que o sujeito recorre a cada vez que um obstáculo se erige em relação à satisfação pulsional. Como tais obstáculos são onipresentes, tem-se que a fantasia é também onipresente em sua função de produzir al guma homeostase psíquica e Freud manifestou repetidas vezes sua surpresa em relação à acentuada capacidade de fantasiar do neurótico. Há, assim, na neurose, certa genealogia que vai da pulsão ao sintoma, passando pela fantasia:

Pulsão $\longrightarrow$ Fantasia $\longrightarrow$ Sintoma

Freud chamou a atenção para esse aspecto no segundo artigo sobre a psicologia do amor, de 1912, intitulado "Sobre a mais geral degradação da vida amorosa", no qual afirmou, manifestando ele mesmo certo espanto, que algo "na natureza da própria pulsão sexual é desfavorável à obtenção da satisfação plena" (FREUD, 1912/ 1996, p.182). Tal conclusão, enunciada de forma aparentemente anódina, foi tomada por Lacan como um verdadeiro axioma da teoria psicanalítica da pulsão e, no Seminário 11 (1964/ 1979), no qual retoma os fundamentos da psicanálise, ${ }^{6}$ ele sublinha tal característica para ver nela o real em jogo na própria pulsão, o real enquanto o impossível de se satisfazer. Voltaremos a este ponto essencial em seguida ao tratarmos da pulsão de morte.

De fato, o terceiro despertar foi o do fundamento mortífero da pulsão em sua exigência imperiosa de satisfação absoluta. $E$, nessa direção, talvez se possa considerar a análise que Freud faz da religião como um corolário de sua longa tra vessia dessas diversas dimensões de despertar. Apenas tendo atravessado estas três dimensões - sonho, fantasia, delírio - Freud teria podido anunciar um despertar em relação à religião e à ilusão que lhe é inerente.

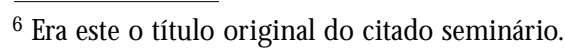


É digno de nota que "O futuro de uma ilusão" tenha sido escrito no período imediatamente posterior à grande virada operada por Freud com o "Mais-além do princípio de prazer". Ao introduzir a pulsão de morte nesse trabalho, Freud pôde dar à pulsão seu verdadeiro e radical estatuto, de força, pressão (Drang) que almeja a satisfação absoluta, denominada por Freud de morte e, mais adiante, por Lacan, de gozo. Recapitulo esse momento da construção freudiana considerandoo como uma conclusão à qual toda sua teoria da pulsão parece ter se dirigido desde o começo. Com o segundo dualismo pulsional, que passa a opor pulsões de vida e pulsão de morte, Freud de fato passa a considerar duas ordens de pulsão: as pulsões de vida (que, no fundo, são as pulsões sexuais do primeiro dualismo), que por sua própria natureza fazem muito barulho, e a pulsão de morte, que opera em silêncio.

Lacan ressal tou por diversas vezes a importância do Mais-além no conjunto da obra de Freud, texto que foi objeto de grande repúdio por parte dos psicanalistas de modo geral. No seminário sobre 0 s quatro concètos fundamentais da psicanálise, Lacan afirma que "toda pulsão é pulsão de morte" (LACAN, 1964/ 1979, p.195 e p.243) e, se ele o faz, é preciso reconhecer que tal afirmativa pode ser encontrada no próprio texto de Freud, ainda que ali isto não seja dito dessa maneira. Mas basta que se leia com atenção a sétima seção do Mais além - composta de apenas duas páginas e meia, que se sucedem às seis longas e densas seções desse ensaio de cerca de 70 páginas - , para se concluir, com Lacan, que o que Freud se empenha em demonstrar nessa conclusão é que toda pulsão é pulsão de morte: " [...] as pulsões de vida têm muito mais a ver com nossa percepção interna; de fato, surgem como revoltosas, sem cessar trazem tensões cujo alívio é sentido como prazer, enquanto que as pulsões de morte parecem realizar seu trabalho com discrição. 0 princípio de prazer parece estar diretamente a serviço das pulsões de morte" (FREUD, 1920/ 1996, p.61). Evidentemente, não faremos aqui um estudo comparativo da teoria da pulsão em Freud e Lacan, o que nos colocaria um bom número de importantes e difíceis questões. Trazemos, em seguida, apenas nosso esforço de conjugar a derradeira teoria freudiana da pulsão com a ênfase posta por Lacan na dimensão do gozo, atribuindo a esta a qualidade definida por Freud como a morte, o que pudemos desenvolver com mais detalhes em outro artigo (JORGE, 2003).

A pulsão apresenta um vetor na direção da satisfação absoluta - morte (Freud) ou gozo (Lacan) - e, se tal busca de satisfação absoluta encontra algum freio, isto se dá pela entrada em ação da fantasia inconsciente como sendo aquele fator que sexualiza a pulsão de morte e a transforma em pulsão sexual. Assim, toda pulsão sexual é, no fundo, também pulsão de morte, apenas que freada em seu empuxo na direção do gozo absoluto - daí Lacan insistir em que toda pulsão é, no fundo, pulsão de morte. A não-sexualização da pulsão de morte, efeito da 
não-entronização da fantasia pela falha do recalque originário, é o que se passa na psicose, na qual Lacan observa que o inconsciente está "a céu aberto". Em outros processos patológicos, como, por exemplo, as toxicomanias graves, a fantasia parece sofrer uma rarefação progressiva, que dessexualiza paulatinamente a pulsão e a faz emergir em seu radical direcionamento rumo ao gozo e à morte.

No diagrama a seguir, vê-se as quatro dimensões do despertar e sua posição relativa à teoria da pulsão na obra de Freud:

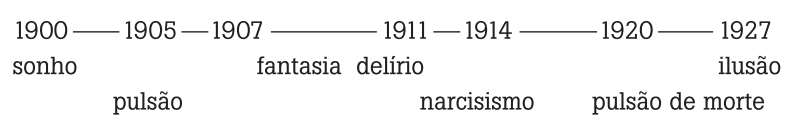

\section{...E ILUSÃO}

Consideradas por Freud como "a peça talvez mais importante do inventário psíquico de uma cultura" (1927/ 1996, p.14), as idéias religiosas são por ele tomadas enquanto verdadeiras "ilusões". Mas que estatuto dar a essa ilusão? Freud aproxima a ilusão inerente à religião mais do delírio do que da fantasia (1927/ 1996, p.52) , embora “uma ilusão não seja a mesma coisa que um erro; tampouco é necessariamente um erro" (FREUD, 1927/ 1996, p.30). Pois o que caracteriza as ilusões é que elas são derivadas de desejos humanos. Aproximam-se, assim, dos delírios, mas diferem deles: os delírios estão em contradição com a realidade. Já as ilusões não precisam ser necessariamente falsas, ou seja, irrealizáveis ou em contradição com a realidade. Freud afirma que podemos "chamar uma crença de ilusão quando uma realização de desejo constitui fator proeminente em sua motivação" (1927/ 1996, p.31), de modo a que nós desprezemos sua relação com a realidade tanto quanto a própria ilusão não dá valor à verificação. As doutrinas religiosas são todas elas ilusões e, algumas delas, podem ser comparadas a delírios.

A religião é um discurso que constitui uma fantasia com características particulares, uma fantasia que se aproxima do delírio - ou talvez uma "fantasia delirante", segundo a curiosa expressão utilizada por Freud, aparentemente uma única vez, no ensaio sobre a Gradiva (FREUD, 1907/ 1996, p.43) - na medida que pretende suturar o real. A religião é um "tesouro de representações, engendrado pela necessidade de tornar suportável o desamparo humano" (FREUD, 1927/ 1996, p.18). A posse dessas idéias, prossegue Freud, protege o homem "em dois sentidos: contra os perigos da natureza e do Destino, e contra os danos que 0 ameaçam por parte da própria sociedade humana" (idem). Freud observa que, aqui, reside, segundo seus próprios termos, "a essência da questão" (idem): trata-se de produzir um sentido mais elevado para a vida, que passa a ser compreendida como um estágio de aperfeiçoamento da alma humana. 0 ponto nuclear desse 
discurso que visa dar sentido à vida não poderia ser outro senão o da morte. $\mathrm{E}$ a morte passa a ser objeto dessa produção de sentido: a própria morte passa a ser considerada não mais como "um aniquilamento, um retorno ao inanimado inorgânico, mas o começo de um novo modo de existência que se acha na via rumo ao desenvolvimento superior" (FREUD, 1927/ 1996, p.19).

0 poder inerente ao discurso religioso depende dessa contínua produção de sentido expressa em seu grau máximo através do sentido que é outorgado àquilo que não tem nenhum sentido - a morte. Pois a morte é um dos nomes do real e talvez seja o melhor deles, algo que opera a radical perda do sentido. É interessante observar que o próprio Freud situa a necessidade de ultrapassar esta idade religiosa como um "despertar intelectual" (1927/ 1996, p.39) das massas.

\section{FREUD, PFISTER E “A ESSÊNCIA DA QUESTÃO”}

A relação de amizade entre Freud e o pastor Oskar Pfister foi, de fato, ocasião para um longo diálogo sobre o sentido da religião. Pfister foi um dos primeiros psicanalistas não médicos e um pioneiro em fazer uma conexão entre a psicaná lise e a pedagogia, assim como a estender o tratamento psicanalítico a crianças e adolescentes. Membro fundador da Sociedade Psicanalítica Suíça, Pfister manteve uma afetuosa correspondência com Freud durante cerca de 30 anos.

Quanto a isso, cumpre notar que um grande número de interlocutores de Freud era de outros lugares que não Viena: Fliess, de Berlim, Ferenczi, de Budapeste, Jung e Pfister, de Zurique. Isso significa que o Outro com o qual Freud dial oga encontra-se mais além de Viena e cabe perguntar, assim, se o fato de ele não encontrar um verdadeiro interlocutor em Viena não seria uma das causas essenciais de seu ódio em relação a essa cidade. Numa carta a Fliess, por exemplo, quando Freud combinava com seu amigo um congresso (quando os dois se encontravam, tratava-se de um congresso) em Berlim, ele diz que a única coisa que 0 desagradava era saber que, quando retornasse aViena, odiaria essa cidade três vezes mais do que antes. Retornar aViena significava voltar a esse lugar onde se encontrava só e sem pares que o ouvissem. Sabemos que no ódio, situado na junção entre o real e o imaginário, é o simbólico que falta (LACAN, 1953-54/ 1979, p.309).

A correspondência Freud-Pfister tem momentos saborosíssimos, como o da carta de 25/ 11/ 1928, na qual Freud, numa conhecida passagem, declara: "Não sei se o senhor adivinhou a ligação secreta entre a Análise lèga e o Futuro deuma ilusão. Na primeira, quero proteger a análise dos médicos, na segunda, dos sacerdotes. Quero entregá-la a uma categoria que ainda não existe, uma categoria de curas de alma seculares, que não necessitam ser médicos e não podem ser sacerdotes" (FREUD \& MENG, 1998, p.167). Por outro lado, quando o "Mal-estar na cultura" é publicado, Pfister se apressa em manifestar, numa carta de 4/2/1930, sua 
discordância em relação à pulsão de morte: “Na doutrina das pulsões o senhor tem pensamento conservador, eu progressista. [...] Vejo a 'pulsão de morte' somente como declínio da 'força vital', não como uma pulsão propriamente dita [...]" (idem, p.173 e p.174). Três dias depois, na carta de 7/2/ 1930, Freud Ihe responde que a pulsão de morte é "novamente um caso da luta entre ilusão ( realização de desejo) e reconhecimento. Não se trata de modo algum de aceitar o que seja mais agradável ou mais cômodo e vantajoso para a vida, e sim o que mais se aproxima da enigmática realidade que existe fora de nós. A pulsão de morte não me é um anseio de coração, ela surge somente como uma hipótese inevitável a partir de razões biológicas e psicológicas" (idem, p.176).

É muito relevante para a nossa perspectiva notar ainda que, numa carta de 9/2/ 1909, portanto, situada logo no início do contato entre eles, durante o período em que Freud estudava a fantasia - e a pulsão não Ihe revelava senão sua face sexual, de vida - , os termos de Freud quanto à religião não lembram nem um pouco os de 1927. A religião não é de modo algum situada, aqui, como uma ilusão, e Freud revela uma tolerância em relação a ela que não seria mais encontrada em 1927: "A psicanálise não é em si religiosa nem anti-religiosa, mas um instrumento apartidário do qual tanto o religioso como o leigo poderão servir-se, desde que aconteça tão somente a serviço da libertação dos sofredores" idem, p.25).

Se tomarmos o ensaio que Oskar Pfister escreveu como resposta ao "Futuro de uma ilusão", ironicamente intitulado "A ilusão de um futuro", vê-se que o problema do sentido que é buscado pela religião domina todo o texto, que, aliás, Freud não só incentivou que ele escrevesse como também publicou na revista Imago de 1928. Nele, Pfister se empenha em negar, uma por uma, as "acusações" que ele aponta Freud ter feito à religião: a religião como obsessão neurótica, como configuração do desejo, como hostil à razão, como proteção (policial) da cultura. Sua conclusão desemboca na idéia de que a religião "se ocupa com a pergunta pelo sentido e valor da vida" (PFISTER, 1928/2003, p.53). Pfister corrobora, assim, aquilo que Freud considerava como "a essência da questão": a religião como algo que é valorizado pelo fato de atribuir sentido à vida, e, para tanto, necessita elidir o não-senso inerente à morte.

A abordagem da religião, iniciada em "O futuro de uma ilusão", prossegue em "Mal-estar na cultura". Se naquele Freud colocou que "a cultura corre um maior perigo aferrando-se a seu vínculo atual com a religião do que desatando-o" ( 1927/ 1996, p.35), nesse ele reafirma sua formulação de que "só a religião sabe responder à pergunta sobre o propósito da vida" (FREUD, 1930/ 1996, p.75 e p.76).

Dos quatro grandes caminhos do homem, considerados classicamente como sendo a arte, a ciência, a filosofia e a religião, a psicanálise sempre manteve uma relação de troca constante com os três primeiros e apenas em relação à religião, como um discurso, Freud produziu uma reflexão opositiva com a psicanálise. Ao 
contrário, as artes plásticas e literárias, as ciências biológicas e antropológicas, e as filosofias, de Parmênides a Schopenhauer, sempre enriqueceram a visão psica nalítica e forneceram a ela elementos com os quais ela pôde articular suas descobertas. Quanto à religião, Freud escreveu um texto duramente crítico e opositivo. Acredito que, se isso ocorre, é na medida em que psicanálise e religião constituem dois modos radicalmente opostos de operar com o sentido: a religião opera fechando o sentido, ao excluir dele o real, ao passo que a psicanálise, incluindo0 , opera abrindo o sentido.

\section{EFEITO DE SENTIDO REAL}

Em 1974, em RSl, Lacan colocou como um verdadeiro projeto de todo o ano de seminário o delimitar ao máximo o que pode ser o real de um efeito de sentido: "O efeito de sentido a se exigir do discurso analítico não é imaginário, não é também simbólico, é preciso que seja real" (LACAN, 1974-1975). Embora o sentido seja, enquanto tal, da ordem do imaginário, Lacan introduz aí a idéia do ééto de sentido ligado ao real.

Deriva daí a concepção psicanalítica da interpretação, retomada por Lacan a partir da tripartição RSI. A interpretação é da ordem do equívoco, do W itz, ela é suspensão do sentido dado e jamais se produz como o sentido do campo do imaginário. Lacan pondera que 0 efeito de sentido a se obter com o discurso psicanalítico não é imaginário, nem simbólico, é real. A interpretação deve ser equívoca, ela "é feita para produzir ondas" (1975/ 1976, p.35), e sua "virtude alusiva" pode ser exemplificada pelo dedo de São João Batista, na última tela de DaVinci, que aponta para o alto, para uma região imprecisa (1958/ 1998, p.648).

0 termo révél (despertar) tem o mesmo radical que rêve (sonho) e dele se origina. Assim como o sonho tem uma função psíquica importante, acredito que o despertar apresenta também uma função psíquica extremamente relevante, ainda que, na maioria das vezes, surja apenas de modo muito pontual, como "hiância" (LACAN, 1964/ 1979, p.58).

Lacan encerra a sessão inaugural de 15/ 11/ 1977 do seminário Le moment de conclure, intitulada "Une pratique de bavardage", dizendo: "O importante é que a ciência é ela própria uma fantasia, e que a idéia de um despertar seja, propria mente falando, impensável" (1977b/ 1979, p.9). No seminário de 19/4/ 1977, Lacan afirma que "o despertar é o real sob seu aspecto de impossível, que só se escreve à força ou por força - é isso que chamamos de contra-natureza" (1977c/ 1979, p.15). Duas lições depois, no seminário de 17/ 5/ 1977, Lacan reforça essa idéia do impossível despertar e, questionando o porquê de não se introduzir "um novo significante que não tivesse nenhuma espécie de sentido", responde que "nós permanecemos sempre colados ao sentido" (1977d/ 1979, p.23). Assim, esse despertar impossível parece estar ligado ao novo significante sem sentido: 
“N ossos significantes são sempre recebidos. Por que não se inventaria um novo significante? Um significante, por exemplo, que não tivesse, como o real, nenhuma espécie de sentido?" (idem, p.21). Sempre recebidos, os significantes conduzem a que "na verdade, a doença mental que é o inconsciente não se desperta" (idem, p.21). A ciência, por sua vez, não conduz ao despertar: "O que Freud enunciou, o que quero dizer, é isto - em nenhum caso há despertar. A ciência só é passível de ser evocada indiretamente nessa ocasião. É um despertar, mas um despertar difícil, e suspeito. Só é seguro que se está despertado quando o que se apresenta e representa é sem nenhuma espécie de sentido" (idem, p.21).

Se o despertar absoluto é impossível, momentos de despertar, pontuais, não são aquilo que a experiência psicanalítica possi bilita? Por outro lado, o despertar absoluto é o que parece estar em jogo no cerne da experiência mística mais radical. $E$, a esse respeito, cabe indagar a emergência da categoria do princípio de Nirvana na obra de Freud, precisamente quando ele dá à pulsão sua feição mais radical, a de ser, em essência, pulsão de morte.

\section{O PRINCÍPIO DE NIRVANA E A PULSÃO DE MORTE}

O princípio de Nirvana, denominação proposta pela psicanalista inglesa Barbara Low (LOW, 1920, p.75), foi mencionado por Freud pela primeira vez em 1920, no "Mais-além do princípio de prazer", para designar a tendência do aparelho psíquico para levar a zero ou reduzir o mais possível a quantidade de excitação de origem interna ou externa. Nesse ensaio, sua definição do princípio de Nirvana é idêntica à do princípio de constância e apresenta a mesma ambigüidade que ela quanto ao tender para o zero e ao tender a manter constante. Quatro anos mais tarde, no artigo sobre "O problema econômico do masoquismo", Freud irá distinguir esses princípios postulando a íntima relação entre o princípio de Nirvana e a pulsão de morte: "O princípio de Nirvana expressa a tendência da pulsão de morte [...]" (FREUD, 1924c/ 1996, p.166). Isto significa que a tendência ao zero do princípio de Nirvana expressa a tendência fundamental do psiquismo, ao passo que o princípio de prazer - que pode ser, ele então, denominado de princípio de constância - é uma modificação que ameniza essa tendência, no sentido de manter constante a excitação sem deixála aumentar.

Principio de Constância

Principio de Nirvana

No fundo, trata-se da mesma tendência que pode ser tomada em seu vetor mais radical ou em seu vetor relativo, mas ambos expressam a mesma direção do vetor. Freud chegará, por fim, a estabelecer as seguintes correlações: princípio de Nirvana como a tendência da pulsão de morte; princípio de prazer como reivin- 
dicação da libido; princípio de realidade, uma modificação do princípio de prazer, como a influência do mundo externo.

De todo modo, é bastante surpreendente que Freud tenha feito referência a um termo oriundo do budismo para designar aquilo que constitui sua definitiva e mais radical postulação sobre a pulsão. 0 esquema a seguir (JORGE, 2003) permite visual izar a pulsão em seu vetor único de pulsão de morte na direção de das Ding, objeto real, impossível, que, caso existisse, proporcionaria a satisfação absoluta; a fantasia como o freio, o filtro, que, ao ser entronizado como conseqüência do recalque originário, sexualiza a pulsão de morte e funda a pulsão sexual; o advento de duas regiões distintas no vetor único da pulsão: a pulsão sexual submetida ao princípio de prazer, e a pulsão de morte, regida pelo mais-além do princípio de prazer:

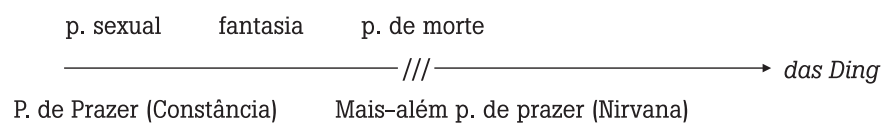

O que significa o termo 'Nirvana'? Jorge Luis Borges pondera que muito do fascínio que o budismo exerce sobre o Ocidente provém da palavra Nirvana que, segundo ele, "tão sonora e enigmática, inclui algo precioso" (BORGES, J. L. \& JURADO, A., 1976/ 1977, p.58). Na língua sagrada dos budistas, páli, que significa texto sagrado e é derivada do sânscrito, é dita nibbana e no chinês ni- pan. Nirvana é palavra sâncrita que significa apagamento, extinção. A palavra não foi cunhada por Buda e é utilizada, ainda, na religião hindu do jainismo. No poema épico M ahabharata, fala-se de Nirvana e muitas vezes de Brahma-nirvana, extinção em Brahma. Para os U panishads, o processo cósmico é o sonho de um deus, mas para o budismo há um sonho sem sonhador. Detrás do sonho e abaixo deste, não há nada. Ou seria melhor dizer - há nada?

Em geral, a palavra Nirvana serve para designar a extinção do desejo humano, 0 aniquilamento da individual idade que se funda na alma coletiva, um estado de quietude e de felicidade perfeitas. É interessante que Freud, em sua teorização radicalmente nova introduzida no Mais além, recorra a uma nomeação oriunda do budismo.

Tomemos a história de Sidharta, que se tornaria o Buda, cujo nome significa "O Desperto". Ela nos é magistralmente contada por Borges, a partir do evangeIho do Nepal e doTibet. Sua mãe, Maya, que significa'ilusão', teve um sonho: em seu flanco entra um elefante de seis presas, tendo o corpo branco como a neve e a cabeça cor de rubi. Os intérpretes do sonho de Maya profetizaram que seu filho seria dono do mundo (um grande rei) ou o seu redentor. Seu pai escolhe a primeira possibilidade e manda erguer para ele três palácios, dos quais exclui tudo o que possa revelar-Ihe a senilidade, a dor ou a morte. Dez anos de felicida- 
de ilusória transcorrem para o príncipe, anos esses dedicados ao gozo dos sentidos em seu palácio, cujo harém abriga nada menos que 84 mil mulheres. Mas Sidharta insiste em ultrapassar os limites ilusórios que lhe foram impostos e acaba por conseguir atravessar os muros dos palácios e, mais além deles, se depa ra com a velhice, a doença e a morte.

A vida de Sidharta é a vida daquele que foi protegido do despertar de todos os modos, mas o buscou, igualmente, de todos os modos. Criado no interior de um cinturão de palácios oníricos, ele buscou se deparar com esse real do trauma que se situa para além da fantasia que Ihe foi proporcionada pela père version. Sidharta atravessou as cercas que lhe criaram um mundo possível para se deparar com 0 i- mundo (Lacan), com o impossível. Sidharta buscou o encontro com o real.

A psicanálise não visa transformar os analisandos-Sidhartas em Budas, mas não podemos esquecer que Lacan chega a situar o analista num lugar homólogo ao da santidade, de rebotal ho da humanidade. 0 despertar é um momento inapreensível na vida humana, mas presente: ele é homólogo ao lugar do sujeito. Ele possui a mesma qualidade do anoitecer, da hora da ave-maria - a hora de transição entre o dia e a noite, pintada, por exemplo, por René Magritte na tela de 1954, 0 império da luz. Trata-se da hora do dia em que é muito freqüente o sujeito sentir angústia: é a hora em que há passagem, travessia, em que o sentido é dúbio, nela não há luz nem tampouco escuridão. Não é hora de sonhar - nem de viver nem de dormir. É hora de morrer. E Buda morreu ao anoitecer.

Recebido em 20/ 1/ 2005. Aprovado em 13/ 4/ 2005.

\section{REFERÊNCIAS}

BORGES, J. L. \& JURADO, A. (1976/ 1977) Buda, São Paulo: Difel.

DIDIER-WEILL, A. (1995/ 1997) Os três tempos da lè, Rio de Janeiro: Jorge Zahar.

FREUD, E. L. \& MENG, H. (orgs.) (1909-1939/ 1994) Cartas entre Freud e Pfister, Viçosa: Ultimato.

FREUD, S. (1996) Obras completas, Buenos Aires: Amorrortu.

(1907) "El delirio y los sueños en la 'Gradiva' de W. Jensen”, v.IX.

(1908) "El creador literario y el fantaseo", v.IX.

(1912) "Sobre la más generalizada degradación de la vida amorosa", V.XI.

(1911a) "Sobre el sentido antitético de las palabras primitivas", v.XI.

(1911b) "Formulaciones sobre los dos principios del acaecer psíqui co", v.XII.

(1914) “Introducción del narcisismo", v.XIV.

(1920) "Más allá del principio de placer", v.XVIII.

(1924a) "Neurosis y psicosis", v.XIX. 
(1924b) "La pérdida de realidad en la neurosis y la psicosis", V.XIX. (1924c) "El problema económico del masoquismo", v.XIX.

(1927) “El porvenir de una ilusión", v.XXI.

(1930) "El malestar en la cultura", v.XXI.

. eW. FLIESS (1887-1904/ 1986) A correspondência completa de Sigmund

Freud para W ilhelm Fliess, MASSON, Jeffrey Moussaieff (org.), Rio de Janeiro: Imago.

JORGE, M.A.C. (2000) Fundamentos da psicanálise de Freud a Lacan - v.1: as bases conceituais, Rio de Janeiro: Jorge Zahar.

. (2003) "A pulsão de morte", in Estudos de psicanálise, n.26, Belo Horizonte: Círculo Psicanalítico de Minas Gerais, p.23-40.

LACAN, J. (1953-1954/ 1979) 0 seminário, livro 1: Os escritos técnicos de Freud, Rio de Janeiro: Zahar.

. (1957/ 1998) "A instância da letra no inconsciente ou a razão desde Freud", in Escritos, Rio de Janeiro: Jorge Zahar.

. (1958/ 1998) "A direção do tratamento e os princípios de seu poder", in Escritos, Rio de Janeiro: Jorge Zahar. - (1962-1963/ 2004) Le séminaire, livre 10: L'angoi sse, Paris: Seuil. - (1964/ 1979) 0 seminário, livro 11: Os quatro conce tos fundamentais da psicanálise, Rio de Janeiro: Zahar. . (1966-1967/ 2003) "A lógica da fantasia", in Outros escritos, Rio de Janeiro: Jorge Zahar.

(1969-1970/ 1992) 0 seminário, livro 17: 0 avesso da psicanálise, Rio de Janeiro: Jorge Zahar.

. (1974-1975) R.S.I., seminário inédito, mimeo.

(1975/1976) “Conférences et entretiens dans des universités nord-américaines", Scilicet, 6/ 7, Paris: Seuil.

(1977a/1978) "Nomina non sunt consequentia rerum", in

Ornicar?, 16, Paris: Lyse.

. (1977b/ 1979) "Une pratique de bavardage", in Ornicar?, 19,

Paris: Lyse.

Paris: Lyse.

(1977c/ 1979) "La varité du symptôme", in Ornicar?, 17/ 18,

(1977d/ 1979) "Un signifiant nouveau", in Ornicar?, 17/ 18, Paris: Lyse.

LOW, B. (1920) Psycho-analysis: a brief account of the Freudian theory, N ew York: Harcourt, Brace \& Howe.

PEIXOTO, E. V. (2003) "A linguagem em seus efeitos constitutivos do sujeito", dissertação de mestrado, U enf, Campos dos Goytacazes, mimeo.

PFISTER, O. (1928/ 2003) "A ilusão de um futuro - um embate amigável com o Prof. Dr. Sigmund Freud", in WONDRACEK, K.H.K. (org.) 0 futuro ea ilusão, Petrópolis: Vozes.

ROUDINESCO, E. (1982/ 1989) História da psicanálise na França - A batalha dos cem anos, vol.1: 1885-1939, Rio de Janeiro: Jorge Zahar. 